\title{
La intervención de tres documentos identificados como alardes de vela
}

María Campoy Naranjo | Centro de Intervención del IAPH

URL de la contribución <www.iaph.es/revistaph/index.php/revistaph/article/view/3970>

\section{RESUMEN}

Tras la reconquista cristiana, Mijas fue uno de tantos enclaves fronterizos forzados a hacer frente a las incursiones enemigas y de piratas africanos. Testigo de esa actividad de vigilancia permanente se conservan tres documentos, identificados como Alardes de Vela, una tipología documental de la que no se han localizado otras referencias documentales, adscrita a concejos municipales emplazados en áreas geográficas estratégicamente relevantes que requerían del obligatorio control de sus fronteras.

La intervención de los documentos llevada a cabo en el Taller de Patrimonio Documental y Bibliográfico del IAPH en junio de 2011 permitió profundizar en el conocimiento de estos documentos.

\section{Palabras clave}

Alardes | Documentos | Instituto Andaluz del Patrimonio Histórico | Intervención | Mijas (Málaga) | Patrimonio documental | 


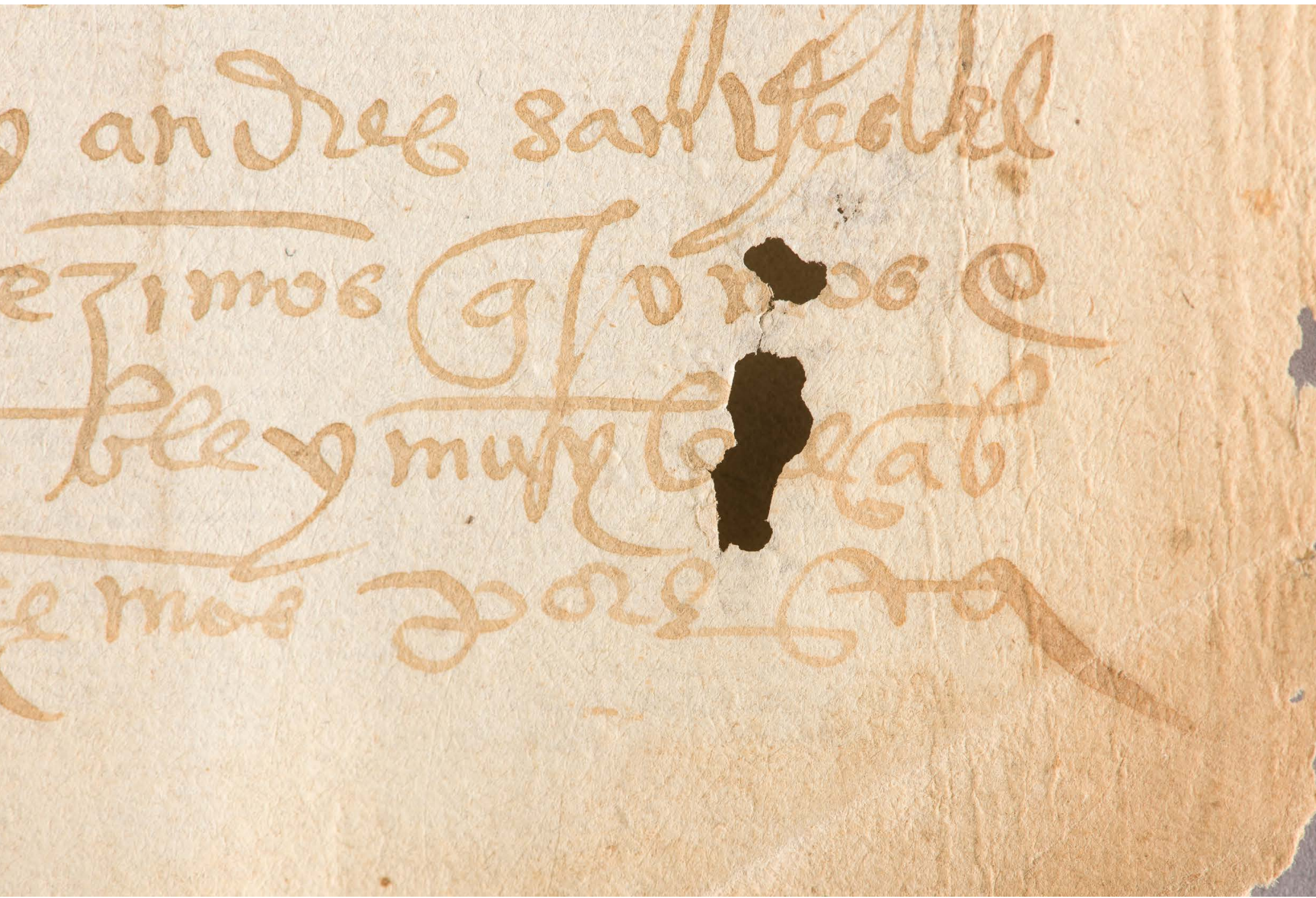

Alardes de vela. Detalle | foto Fondo gráfico IAPH (José Manuel Santos Madrid), autor de todas las fotografías del artítulo 


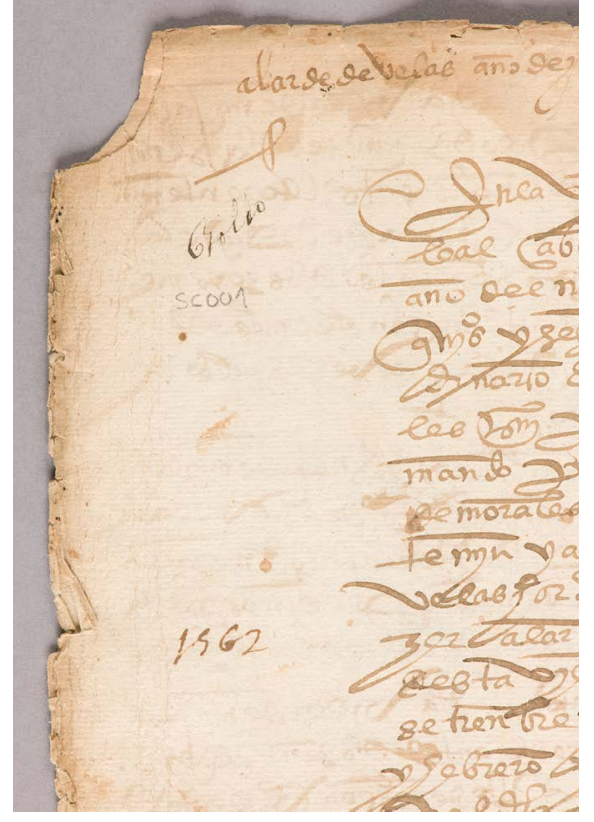

Detalle. Alardes de vela. Estado inicial

Tras la reconquista cristiana, las fortificaciones desplegadas a lo largo de la costa peninsular -herederas naturales de las ciudadelas, fortines, reductos y torres de vigía con las que los musulmanes habían cubierto las fronteras más vulnerables de sus dominios-, combinaron su carácter defensivo con tácticas más sutiles de aviso. Mediante fuegos de noche y humos por el día, se evitaron los acostumbrados rebatos a toques de campana que ponían sobre aviso al enemigo y frustraban cualquier intento de apresarlo antes de su regreso al mar.

Mijas fue uno de aquellos enclaves que desde los tiempos inmediatos a su repoblación, en 1484, se vio forzada a hacer frente a las incursiones enemigas, bien por ser su costa enclave fronterizo con África, bien por constituir un punto estratégico en el control del valle de Suel.

Testigo de esa actividad de vigilancia permanente se conservan en el fondo antiguo del Archivo Histórico Municipal de la $\mathrm{Cala}^{1}$ de Mijas los alardes de vela. Se trata de tres documentos de contenido y estructura similares, adscritos a una tipología documental de la que no se han localizado otras referencias documentales, tal vez porque provenían de concejos emplazados en áreas geográficas estratégicamente relevantes que requerían el obligatorio control de sus fronteras.

En cualquier caso, los tres documentos constituyen una fuente documental determinante y que da fe de las labores de vigilancia a las que se vieron sometidas las costas de Mijas frente a las incursiones enemigas o de piratas africanos. La Real Academia Española entiende, entre varias acepciones, por alardes "revista o inspección por parte de un superior de las personas o cosas sometidas a su autoridad o a su cuidado"; y por vela "centinela o guardia que se ponía por la noche en los ejércitos o plaza".

La labor de vigilancia de Mijas corría a cargo de un grupo de "velas", llamados también guarda o escuchas, apostados largos periodos de tiempo en las torres que acotaban el territorio y de las que aún quedan en pie la torre de Calahorra, la de Torrevieja y la de Torrenueva. De la lectura del documento se desprende que el alarde de vela constituía la declaración jurada e individual ante la autoridad de cada uno de los vigías de haber realizado el servicio sin contratiempos. Un trámite necesario al ser la vigilancia fronteriza jurisdicción de la ciudad de Málaga, a la que había que rendir cuentas y certificar la correcta ejecución de los servicios, para que los velas pudiesen percibir sus honorarios del proveedor general de la armada de su majestad.

La MORADA de nuestra Memoria. Archivo Histórico Provincial de Mijas. Catálogo de la exposición. Mijas, del 9 al 16 de noviembre de 2007. La Cala de Mijas, del 9 al 26 de mayo de $2008<$ http://www.mijas.es/portal/files/adjuntos/cultura/archivoHistorico/a8._La_Morada_de_nuestra_Memoria.pdf $>$ [Consulta:1/9/2017]

La vigilancia de las costas estaba perfectamente regulada por las ordenanzas promulgadas por los reyes católicos en 1497. En las mismas se estipulaba la necesidad de transmitir los rebatos a las poblaciones más próximas de poniente y levante de manera inmediata, sin hacerse notar al enemigo, 
mediante el uso de señales ópticas en función del número de barcos que se aproximase. Entre las obligaciones, el correcto cumplimento del servicio pasaba por la prohibición de dormir, estar acompañado de mujeres, jugar o poseer perros, hurón, lazos, redes o cualquier otro tipo de aparejo de cazar y pescar, bajo pena de cárcel. También contemplaba premios en metálico a los guardas que avistasen al enemigo.

Los tres documentos certifican las vigilancias efectuadas en las murallas de Mijas entre los años 1561 y 1563. Realizado en soporte de papel de fabricación artesanal procedente de distintos molinos papeleros, cada documento se redacta en un bifolio de $318 \times 219 \mathrm{~mm}$ plegado por la mitad y manuscrito en todas sus caras en escritura cortesana.

El primero, fechado en 2 de marzo de 1562, corresponde a la vigilancia efectuada desde primeros de septiembre de 1561 a febrero del año siguiente; el segundo documento está fechado en 22 de marzo de 1563 y corresponde a la vigilancia realizada entre septiembre de 1562 y febrero siguiente; y el tercero y último, fechado en 27 de octubre de 1563, corresponde al turno de marzo a octubre del año mencionado. Los turnos de vigilancia se prolongaban durante seis meses y los relevos se efectuaban entre febrero y marzo y entre septiembre y octubre. La dotación del personal estaba formada por seis individuos o velas, y contaban con la posibilidad de incrementar su número en caso de peligro. Se desconoce el reparto y turnos de rotación.

El perfil de los vigilantes también se recoge en las citadas ordenanzas. Todos eran vecinos de Mijas, sin formación especial, y sólo se exigía que fuesen "ombres de campo, mancebos y sueltos y sanos e que thengan conocimiento de las cosas de la mar e de la tierra [sic]". En ningún caso se requería la presencia de soldados profesionales.

Durante los trabajos de intervención ${ }^{2}$ llevados a cabo en el Taller de Patrimonio Documental y Bibliográfico del IAPH en junio de 2011, se comprobó que los tres documentos carecen de orificios de cosido y por lo tanto nunca estuvieron encuadernados. La concepción independiente de cada uno de ellos, con su correspondiente intitulación, datación y firmas de validación, puede explicar que no estuviesen cosidos ni encartados en cuadernillos, si bien lo lógico habría sido que formasen parte de un expediente ordenado cronológicamente.

Dentro de la actividad del concejo de Mijas este tipo de documentos debió constituir una tipología de carácter sistemático. Quizá los papeles permaneciesen sueltos a la espera de reunirlos en un volumen. Desafortunadamente, la ausencia de una encuadernación propició la dispersión y pérdida de la mayor parte de la documentación y los tres documentos constituyen la única fuente documental de esa actividad de vigilancia en Mijas.

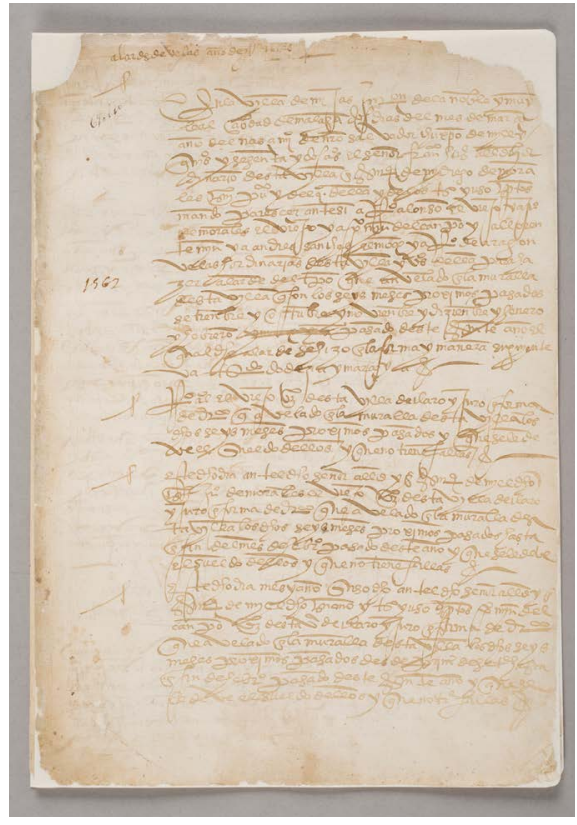

Alardes de vela. Estado final

2

Productos de difusión de los trabajos de intervención:

ALARDE de Velas (1562-1563). iaphtube, 24 de agosto de 2012 <https://www.youtube.com/watch?v=k7Pz3C5C0jY> [Consulta: 01/09/2017]

ALARDE de Velas. Mijas. Málaga. Catálogode obras restauradas. Web Instituto Andaluz del Patrimonio Histórico <http://www.iaph.es/ web/canales/conservacion-y-restauracion/catalogo-de-obras-restauradas/contenido/Alarde_de_Velas> [Consulta: 01/09/2017]

MEMORIA final de intervención. Alarde de velas (1562-1563). Archivo Municipal de Mijas. Málaga. Sevilla, junio de $2011<$ http:// www.iaph.es/export/sites/default/Webmaster/ 20110610base/resources/documentos/MEMORIA_FINAL_Alarde_de_Velas_MIJAS_ web.pdf> [Consulta: 01/09/2017] 